\title{
Fragmentos de uma história íntima da tradução
}

\author{
Márcia Atalla Pietroluongo*
}

Theodore Zeldin, em seu livro Uma história intima da humanidade (2008), propõe-se a retratar, em cada capítulo, a história de uma pessoa viva comum, descrevendo sua vida e seus fantasmas familiares. Seu objetivo é o de mostrar, por um lado, como os gestos, reações e sentimentos mais pessoais são marcados por heranças geracionais, posto que nossa "mente é um refúgio de ideias que datam de muitos séculos diferentes, tal como as células do corpo têm idades diferentes, renovando-se ou enfraquecendo em ritmos variáveis" (p. 7). Ele coloca em evidência de que maneira e em que intensidade as singularidades individuais se afinam e dão prosseguimento à experiência de gerações anteriores.

Por outro lado, o historiador busca salientar a possibilidade de uma releitura das histórias individuais que pode criar novas perspectivas de futuro. Em suas palavras, “as pessoas podem formar uma nova opinião de sua própria história pessoal e de todo o registro da crueldade humana, seus equívocos e alegrias. Para se ter uma visão nova do futuro, é necessário adquirir uma nova visão do passado" (p. 7). Assim, ele parte não da "história catalogada como nos museus, com cada império e período cuidadosamente destacados" (p. 8), mas do "que ainda não se sedimentou, sobre o passado que permanece vivo na mente das pessoas" (p.8).

Há muito poucas reflexões no campo dos Estudos da Tradução sobre o que poderíamos igualmente chamar de uma história íntima da tradução e sobre as possíveis repercussões das histórias pessoais que são levadas por alguma necessidade objetiva a ser traduzidas por um tradutor público. Não é minimamente incomum no âmbito da tradução oficial que o tradutor se

\footnotetext{
${ }^{*}$ Universidade Federal do Rio de Janeiro.
} 
depare com a humanidade em seu caráter mais reservado e mais sigiloso através dos documentos que lhe são destinados, que acabam por devassarlhe a vida dos clientes.

Com efeito, incontáveis são as histórias de vida que os tradutores são chamados a traduzir, muitas delas suscitando uma enorme emoção e, até mesmo em alguns casos, uma grande comoção. É esta proximidade nem sempre tão desejável com a vida e a intimidade do outro, é este trânsito muito tênue entre o público e o privado, e as ressonâncias e questionamentos que tal imediação e circulação podem acarretar no trabalho e na vida pessoal do tradutor público que serão esboçados aqui através de brevíssimos relatos de histórias particulares que se tornaram casos levados a juízo, sobretudo em varas de família.

Uma parte relevante dos documentos que são dados a traduzir ao Tradutor Público por clientes privados, mas também pelos Tribunais aos quais ele, porventura, seja credenciado, constituem questões relacionadas ao direito de família que delibera sobre casamento e união estável, direito dos filhos, pensão alimentícia, separação judicial e divórcio, bem como sobre causas que impliquem o regime de bens e patrimônio dos cônjuges, e ações de investigação de paternidade, entre muitas outras que incluam a proteção da pessoa e da família.

Estamos aqui no fulcro da vida do homem em seu caráter mais privado e seguramente diante da grandeza e da miséria humanas em todo seu esplendor. Guerras viscerais entre os cônjuges por pensões, bens e patrimônio, assim como duelos insanos para obter a guarda dos filhos ou, ao contrário, para impor ao outro a guarda dos mesmos, são realmente lugar comum nas varas de família.

Em nosso cotidiano, ações para obtenção de pensões alimentícias para os filhos de pais estrangeiros ocupam copiosamente o judiciário e significativamente o tradutor com traduções de cartas rogatórias, citações, intimações, ações, etc. Com muita frequência, ao que parece, tudo se passa como se a volta dos estrangeiros ao país de origem os destituísse de qualquer laço de paternidade e das correlativas obrigações para com os filhos brasileiros, obrigando as mães, muitas vezes através da justiça gratuita, a um périplo de ações de reivindicação de módicas pensões alimentícias para 
receber mínimos recursos para seus filhos que são, entretanto, expressivos para ambos.

Ações de investigação de paternidade transitam igualmente ao nível internacional. Um caso curioso por sua argumentação é o de um francês, citado em ação de paternidade, que se recusava terminantemente a fazer o exame de DNA. Nas razões elencadas por esse suposto pai, ele declarava ter sido enganado pela mulher brasileira que mal conhecera e denunciava o que chamava de comércio da maternidade, no qual mulheres se aproveitavam sorrateiramente de pequenos descuidos masculinos. Embasando seu raciocínio, citava um estudo sobre paternidade efetiva desenvolvido conjuntamente pelo Departamento de pesquisa em genealogia da Universidade de Niort e pela Universidade de Medicina de Salzburg 2, que havia sido publicado numa revista on-line ${ }^{1}$.

A referida pesquisa tinha como objeto o tratamento das doenças genéticas e buscava elucidar se a medicina atual não estaria atribuindo um lugar desmedido à genética, com o intuito de determinar que tipo de conduta médica e tratamento preconizar diante da eventualidade de tais doenças. Para tal, foram efetuados testes em mais de 3.000 voluntários pares de pais e filhos, cujos pais tinham certeza inequívoca de sua legítima paternidade. Segundo o relato do pai sob suspeita no documento dado a traduzir, os primeiros resultados desse estudo chocaram a equipe de cientistas que constatou que $21 \%$ dos pares pai-filho submetidos ao teste não tinham nenhum vínculo genético, e que 6\% tinham apenas um laço genético de segundo grau, o que significava considerar que o verdadeiro pai biológico dos filhos examinados seria na verdade um irmão, um primo, um pai, ou mesmo um avô do pretenso pai.

O requerido em questão citava a publicação que afirmava que "mais de um filho em cada quatro não seria filho biológico de seu pai, o que poderia motivar os médicos a tomar menos em consideração a prevenção das doenças genéticas". Ora, da mesma forma, segundo seus argumentos traduzidos, ele estaria sendo acusado injustamente e sendo vítima dessa "es-

\footnotetext{
${ }^{1}$ http://rumeursdunet.com/test-de-paternite-la-scandaleuse-realite/
} 
candalosa realidade", urdida por mulheres sonsas, traiçoeiras e interesseiras, e sendo coagido a assumir uma paternidade que não era dele...

Infelizmente, não acompanhei o caso até o final e não tive acesso à tradução de novos documentos que pudessem atestar o resultado dessa conturbada investigação e os contornos jurídicos tomados. Porém, a briga por uma não responsabilização ou por uma menor responsabilização pelos filhos se trava independentemente do sexo do genitor, como atesta outro documento traduzido.

Nesse outro documento, a mulher brasileira deixa três filhos menores na Suíça sob a responsabilidade e os cuidados do ex-marido para se casar de novo no Brasil com um homem de alto poder aquisitivo que lhe exigia uma vida social intensa que a impedia de estar disponível para a vida materna. Em suas alegações, ela enfatizava que a Suíça era inequivocamente um país muito mais adequado para educar os filhos, e a educação das crianças ficaria muito prejudicada no Brasil, país conhecidamente sem estrutura para educar convenientemente os filhos. E afinal eles não ficariam tão distantes assim e as crianças poderiam vir sempre que quisessem, pois a casa dela seria a casa dos filhos no Brasil...

As pendengas judiciais não se esgotam absolutamente em questões de responsabilidade paterna e materna. Inúmeros casamentos encerram-se traumaticamente com traições de toda natureza, ações em varas empresariais no caso de cônjuges que, além da sociedade conjugal, tenham tido em comum empresas de natureza comercial e/ou profissional. Alguns e algumas fazem valer o fato concreto de que um casamento é efetivamente um contrato e um empreendimento que deve ter fins lucrativos.

Nessa perspectiva, todos os meios e recursos parecem ser válidos na tentativa de abocanhar a maior parte possível da fatia de bens conjunta: falsificação de documentos, falsificação de assinatura do cônjuge, obtendose surpreendentemente inclusive o reconhecimento da firma por semelhança em cartórios da cidade, denúncia falsa de violência doméstica, roubo, intimidação de toda a natureza, contratação de assaltantes profissionais, tentativa de manipulação de juízes, dentre outras inúmeras formas inventivas de constrangimento e de coação. 
Um caso digno de interesse pelo questionamento humano que suscita ocorreu quando um casamento de toda uma vida, com vínculos em sociedades empresariais, terminou por uma longa traição do marido que veio a público de forma irremediável, tendo atingido uma zona de visibilidade e desconforto que impossibilitou qualquer remendo da situação, e acabou por desaguar em verdadeira batalha com seguidas intimidações e visitas-surpresa de oficiais de justiça. Neste caso, é humanamente impossível não se interrogar sobre o que poderia ter unido aqueles dois estranhos por tantos anos... Que fatores são esses que não se confundem de forma alguma com qualquer sentimento de natureza afetiva, mas que são fortes o suficiente para vincular os casais por um longo e tenebroso inverno?

Fato é que se tratava de um abastado casal, cujos bens ultrapassavam em muito o território nacional com propriedades nos Estados Unidos e na Europa, mais precisamente na Suíça e em Paris, o que acarretou a necessidade de contratar advogados nas diferentes jurisdições e tradutores públicos de inglês e de francês. Muitos foram os documentos traduzidos e vertidos para essas duas línguas, oriundos dos processos de divórcio litigioso; sequestro de bens; busca e apreensão; arrolamento de bens; inventário e partilha de bens, além de escrituras, certidões, documentos financeiros, emails entre os advogados, etc.

Os momentos mais ou menos pungentes foram se sucedendo com suas contingências. Um deles foi a disputa entre os advogados franceses de ambas as partes que tratavam dos impasses resultantes da luta travada pelo casal em relação aos bens que tinham na França. Com muita ironia e sarcasmo, os advogados esgrimiam num exercício discursivo muito próprio à cultura francesa. Desses que na França é puro prazer retórico e que, no Brasil, chegaria seguramente às vias de fato. A quebra de braço no Brasil é física e, na França, para espanto dos brasileiros, uma discussão que nos parece irascível e demolidora, em que a estima do outro é completamente rebaixada a nossos olhos culturais, muito frequentemente representa apenas um exercício de verve, eloquência e argumentação.

Alguns futuros cônjuges, contudo, são mais prudentes e tentam se precaver com contratos pré-nupciais. Tal foi o caso da tradução do casamento entre pessoas do mesmo sexo entre um engenheiro francês e um 
estudante brasileiro oriundo do interior do país, com a módica diferença de idade entre os dois de 40 anos. Cuidando para a lisura das bodas futuras, ambos estabeleceram previamente, com toda probabilidade por pressão do parceiro sênior, um contrato de casamento com separação total de bens, no qual eram estipuladas as obrigações de cada cônjuge que contribuiria na proporção de suas respectivas possibilidades para o sustento da família. Outros documentos traduzidos atestavam que o engenheiro já havia sido ligado por um Pacto civil de solidariedade (Pacs), o similar na França à nossa escritura pública de união estável, a outro jovem estudante, também de uma cidade do interior do Brasil, este com apenas trinta anos a menos do que o parceiro.

Para além do impacto que pode ter sobre nós o contato com o cliente e sua dor, ansiedade, aflição, saliento igualmente o impacto que o próprio documento a traduzir pode causar. Os documentos atestam, são rastros de vida, são fontes de informação privilegiada. Assim como o historiador se serve de documentos que constituem o registro de eventos, denominados fontes históricas, para reconstituir fatos passados, assim também o tradutor entra em contato com mínimos detalhes da vida dos clientes através dos documentos que lhe são dados a traduzir.

A primeira vez que traduzi uma certidão de óbito, não bastasse o tipo de documento, era ainda o de uma jovem esposa morta precocemente, e a primeira vez que traduzi uma certidão de nascimento cujo único nome masculino era o do próprio titular, certidão sem pai e respectiva ascendência, e sem ascendência paterna também pelo lado materno, pois constavam apenas três nomes na certidão, o do titular, o da mãe e o da avó materna, fui tomada por uma grande comoção e passei dias digerindo o choque dessas tragédias pessoais.

O que essas histórias têm em comum? Como primeira resposta, a dimensão humana e, em alguns casos, dramática e trágica da tradução de documentos que desvelam a vida dos implicados. Como segunda aproximação, esses documentos parecem retratos inequívocos da ausência e da instabilidade sobre as quais tantos laços afetivos se fundam na atualidade. Impossível não identificar ali os traços apontados por Zygmunt Bauman em muitas de suas obras, nas quais ele vem desenvolvendo o conceito de 
modernidade líquida, fundamentada na fluidez, no caráter volátil, incerto e inseguro das relações e instituições no momento atual que priorizam o imediato, o consumo, a superficialidade e o gozo.

Em Amor líquido, o sociólogo disserta sobre as contradições e sobre a fragilidade dos laços observados nas relações amorosas na contemporaneidade. Ele relata que

\begin{abstract}
O principal herói [de seu] livro é o relacionamento humano. Seus personagens centrais são homens e mulheres, nossos contemporâneos, desesperados por terem sido abandonados aos seus próprios sentidos e sentimentos facilmente descartáveis, ansiando pela segurança do convívio e pela mão amiga com que possam contar num momento de aflição, desesperados por "relacionar-se". E no entanto desconfiados da condição de "estar ligado", em particular de estar ligado "permanentemente", para não dizer eternamente, pois temem que tal condição possa trazer encargos e tensões que eles não se consideram aptos nem dispostos a suportar, e que podem limitar severamente a liberdade de que necessitam para - sim, seu palpite está certo - relacionar-se...

Em nosso mundo de furiosa "individualização", os relacionamentos são bênçãos ambíguas. Oscilam entre o sonho e o pesadelo, e não há como determinar quando um se transforma no outro. Na maior parte do tempo, esses dois avatares coabitam - embora em diferentes níveis de consciência. No líquido cenário da vida moderna, os relacionamentos talvez sejam os representantes mais comuns, agudos, perturbadores e profundamente sentidos da ambivalência. (Bauman, 2004, p. 8)
\end{abstract}

A atividade do tradutor juramentado, em suas vertentes mais privadas, confronta-o muito mais do que o desejável com as mazelas humanas mais profundas. Jamais estivera antes a meu alcance imaginar a eloquência tão exibida de tais peças de papel que são levadas à tradução. $\mathrm{O}$ tradutor público, desde sua posse, se depara com o fato de que um documento é uma fonte inesgotável de inferências e suspeitas sobre a vida privada e pública, votando-o a cada trabalho, mesmo que não o queira, a ser uma espécie de detetive da vida de seus clientes (Pietroluongo, 2015). Convém ressaltar que a maioria dos fatos aqui narrados não me foram diretamente contados, a eles tive acesso por meio dos documentos a traduzir.

Longe de buscar delinear perfis psicológicos e muito menos de tomar um partido que não me caberia, pois que a vida é sempre muito maior 
do que a apreensão que possamos fazer dela, uma vez que sua experiência se alarga continuamente e sempre nos escapa, deixando-nos de sobreaviso quanto à impertinência de ousar etiquetá-la, destaco aqui a impossibilidade para o tradutor de uma isenção absoluta quando se lida tão contiguamente com a vida alheia. Na prática, como acompanhar vidas em movimento e não se emocionar? Como não torcer pelo outro em tantos casos? Como não desejar aos clientes em questão que da crise em que se encontram possa resultar alguma equação de vida que possa lhes ser infinitamente mais favorável, mais fecunda, mais acolhedora, mais afetuosa?

Esses casos concretos esboçados apontam para o fato de que o ofício do tradutor juramentado não se esgota na mediação entre autores, textos, línguas e culturas. $\mathrm{O}$ fato mesmo da presença das pessoas em jogo no ato tradutório, da pulsação de suas vidas, exerce um apelo à busca pelo entendimento, suscita dúvidas, perplexidades, questionamentos, e mesmo revoltas, embaçando em alguns momentos os limites sutis entre a objetividade e a subjetividade, pois não há tradutor oficial que, no exercício de sua atividade, possa ser totalmente imune à vida do outro.

Devo reconhecer que a proximidade com cada história pessoal que estabeleço em cada trabalho de tradução tem algum impacto sobre mim. Todas me movem a refletir intensamente sobre os meandros do humano e sobre as particularidades da inserção de um tradutor público que, a cada vez, entra numa história de vida com suas alegrias e vicissitudes, e dela de alguma forma é obrigado a participar no período de sua duração.

Como não se tornar, ainda que da forma mais prudente possível, um participante observador de cada história? Como manter uma distância ideal sendo uma memória viva das histórias traduzidas, conhecendo pormenores íntimos da vida dos clientes? Como não se deixar ocupar nenhum espaço inconveniente que exceda aquele que lhe é atribuído e para o qual foi contratado? Como determinar uma distância que seria a um só tempo neutra e oximoricamente próxima?

Com efeito, uma discrição ótima seria aquela em que a neutralidade não se deixasse confundir em nenhum momento com a indiferença. Porém, essa é uma posição difícil e delicada para o tradutor, podendo mesmo ser embaraçosa. Que possibilidades efetivas ele tem de ocupar esse lugar que 
lhe requer tantas outras competências para as quais ele não foi formado? Tais questões que exigem respostas necessariamente se formulam no dia a dia do ofício, porém não são em geral tratadas em artigos acadêmicos e costumam ser pouco trabalhadas na formação de tradutores, voltada preferencialmente para os inúmeros aspectos teóricos, práticos, objetivos, técnicos e mercadológicos que fazem parte da carreira.

Entretanto, é preciso aprender a se preparar emocionalmente para lidar com a vida alheia, para atuar correta e humanamente, bem como estar apto a se proteger do peso de algumas dessas histórias que podem comover em excesso. É preciso ter um comportamento ético estabelecendo um lugar que não seja distante, mas que tampouco seja invasivo; que seja isento sem deixar que a impessoalidade do trabalho acabe por levá-lo a prestar um serviço friamente burocrático, desconsiderando que há ali com certa frequência pessoas em profundo sofrimento.

Os casos que aqui exponho, delineados em grandes linhas, foram propositalmente destituídos de indícios de identificação que pudessem facilitar o reconhecimento das pessoas reais, com o intuito de acatar a deontologia do ofício do tradutor público e respeitar o termo de sigilo que lhe é imposto com relação às informações a que tem acesso em razão da execução dos serviços de tradução e versão juramentados, privados e públicos prestados. $\mathrm{O}$ mesmo posso afirmar quanto às diretrizes e normas que determinam o código de ética regulamentador de pesquisas acadêmicas que envolvam de diferentes maneiras seres humanos. Como não poderia deixar de ser, eles são norteadores da pesquisa em Estudos da Tradução.

Estes esboços de retratos de vidas em crise em muito se aproximam do material coletado e trabalhado pelo escritor em sua literatura. Um dos clientes cuja história foi aqui sucintamente aludida, em mais uma das repetidas situações melindrosas por que teve que passar, desabafou exclamativo: Esta história parece um romance!? Na impossibilidade de escreverlhe(s) um romance, deixo registradas neste artigo minhas impressões, examinando aspectos do que chamo de uma história íntima da tradução que se inscreve na área temática da tradução e subjetividade.

Assim como o historiador Theodore Zeldin, no livro referido no início, sente necessidade de partir de casos concretos de histórias comuns 
para ilustrar as interseções destas com os objetivos de análise por ele delimitados das relações entre passado e presente, e sobre uma possível reinvenção do futuro de vidas que adquiriram um novo olhar sobre seu passado, evidencio aqui, por um lado, que a convivência com clientes, resultante da necessidade duradoura de traduções por alguns anos, acaba por dar a essas vidas um caráter romanesco para o tradutor que as acompanha. Assim, faço minhas as palavras de meu cliente: sua história daria, de fato, um romance. Todas essas histórias poderiam vir a constituir romances. Cada momento vivido, cada fracasso e cada vitória sobre a crise e o infortúnio ganham o aspecto de capítulos a seguir.

Por outro lado, nos casos descritos, ou nesses romances particulares, desde o início, pelo tom dramático e lancinante de tantos episódios, ficavame claro que se tratava de uma dessas circunstâncias da vida pessoal em que cada um precisaria se reinventar se não quisesse sucumbir a si mesmo e se quisesse sobreviver à crise em que se envolvera, e me restava a interrogação de como cada um deles seria capaz de reler sua própria história criando novas perspectivas para si e para seu próprio futuro. O que ficava patente para quem os acompanhava não tão de perto, mas não tão de longe, durante o período em que a tradução dos documentos era exigida, é que suas novas escolhas seriam definitivas e os novos caminhos que trilhariam ao longo do tempo, suas novas relações e suas novas inserções em vários âmbitos, quando a dor mais aguda se atenuaria, acabariam por levá-los a grandes desafios de ressubjetivação.

\section{Referências}

BAUMAN, Zygmunt. Amor líquido. Sobre a fragilidade dos laços humanos. Tradução de Carlos Alberto Medeiros. Rio de Janeiro: Zahar, 2004.

PIETROLUONGO, Márcia Atalla. As reservas da tradutora In: DANTAS, Marta Pragana (Org). As traduções do francês no Brasil. Campinas: Pontes, 2015. (no prelo)

ZELDIN, Theodore. Uma história intima da humanidade. Tradução de Hélio Pólvora. Rio de Janeiro: BestBolso, 2008. 
Resumo : Breves reflexões sobre o que poderíamos chamar de uma história íntima da tradução e sobre as possíveis repercussões das histórias pessoais que são levadas, por alguma necessidade objetiva, a ser traduzidas por um tradutor público, que se depara com a humanidade em seu caráter mais reservado e mais sigiloso através do teor dos documentos que lhe são destinados.

Résumé : Brèves réflexions sur ce que l'on pourrait appeler une histoire intime de la traduction et les retentissements éventuels que les histoires privées, devant être traduites pour des raisons objectives, peuvent avoir sur le traducteur assermenté qui s'affronte dans l'exercice de sa profession à l'humanité dans ses aspects les plus réservés et les plus secrets à partir du contenu des documents qui lui sont donnés à traduire. 